\title{
Review of methods for sustainability appraisals in ship acquisition
}

\author{
Dina Margrethe Aspen ${ }^{1} \cdot$ Magnus Sparrevik $^{1} \cdot$ Annik Magerholm Fet $^{1}$
}

Published online: 6 August 2015

(c) The Author(s) 2015. This article is published with open access at Springerlink.com

\begin{abstract}
Ship acquisition requires simultaneous consideration of environmental, economic, technological and social performance of candidate design solutions. During the last few decades, multi-criteria decision-making tools have gained popularity as an approach to assisting decision makers when appraising ship design. However, applications are limited to a few methods mostly within the value function class. In this review, we explore the applicability of 12 multi-criteria decision-making methods for typical decision contexts in ship acquisition. Technical and practical method properties are defined before their operational value for evaluations in ship acquisition is assessed. Our results show that a wide range of methods currently not applied offer promising properties in these contexts.
\end{abstract}

Keywords Ship acquisition - Design · Multi-criteria decision making - MCDM - Method selection ·

Sustainability appraisal

\section{Introduction}

Ship acquisition includes the strategic planning, problem preparation, generation of alternatives and commercial activities necessary to support the introduction of new tonnage in a ship-owning company (Cushing 2003). Due to the size, complexity and long lifespan of a ship, decision makers must apply systematic judgement in acquisition

Dina Margrethe Aspen

dina.margrethe.aspen@iot.ntnu.no

1 Department of Industrial Economics and Technology Management, Norwegian University of Science and Technology, 7491 Trondheim, Norway planning and decision making. The conventional technoeconomic performance assessments of a ship are now supplemented with environmental and safety impact considerations to consider the wider sustainability performance over her lifecycle (Ölçer et al. 2004). This system boundary expansion adds to the complexity of the decisionmaking process, involving multiple, often conflicting objectives and criteria. In order to critically appraise sustainability performance, formality and explicit consideration of stakeholder value are necessary.

Ship designers and other primary decision makers involved in new ship acquisition must consider performance during all stages of the ship design process. A ship design evolves in an iterative manner through conceptual, preliminary, contract and detailed design stages. In each step, design parameters such as dimensions, weight, capacities, layout, hull form and systems are revisited until a well-balanced, feasible and preferable solution is identified. The sequencing of these decisions within each stage may differ depending on both the type of ship and strategy of the design team. An excellent overview of various ship design process models is provided in (Andrews et al. 2009; Erikstad and Andrews 2015).

Conceptual ship design defines main characteristics of the ship and allows for basic techno-economic assessments to be made (Eyres and Bruce 2012). This phase often precedes the outline specification, detailing main requirements, objectives and constraints from owners and other invested parties (Erikstad 1996). Preliminary design refines the concept, and more knowledge about the design is acquired. This allows for more sophisticated assessments of lifecycle properties such as environmental and safety performance. At this stage, designers may submit a tender, leaving ship-owning companies with various solutions to compare and evaluate (Dokkum 2011). Contract design 
further forms the basis for agreement between owner and builder and includes precise features of hull, seakeeping, powering and maneuvering. Finally, detailed design (or post-contract design) also adds detailed working plans with instructions for construction and installation for fitters, welders, outfitters and other (Wijnolst and Wergeland 2009).

The introduction of computer-aided ship design (CASD) tools has had a profound impact on ship design decisionmaking process throughout the last five decades (Nowacki 2010). This transition is founded in design theory literature and encompasses knowledge-based design (Coyne 1990), catalog design (Pahl et al. 2007), decision-based design (Mistree et al. 1990, 1991) and optimal design (Papalambros and Wilde 2000). CASD tools allow for rapid and precise generation of graphical representations of ship design with problem-solving capabilities for determining hull form, general arrangement, hydrostatic and hydrodynamic calculations among others. Today, these tools may be viewed as integrated expert systems, constituted by a knowledge base and an inference engine. The knowledge base stores facts about the world and may contain design knowledge and experience from past projects as well as scientific principles and rules, i.e., a form of design catalog. The inference engine is the algorithmic treatment of knowledge to synthesize new information. Inference processes necessary to support design decision making are abduction (synthesis), induction (generation of new knowledge) and deduction (performance assessment) (Coyne 1990; Erikstad 1996). This article concerns performance assessment and aims to evaluate the operational value of various inference logics for decision contexts in ship acquisition.

Designers and other stakeholders must often consider various design solutions across multiple performance metrics during ship acquisition. For this purpose, multicriteria decision-making (MCDM) methods have been devised and applied. These decision algorithms induce an order on a set of alternatives based on the following information:

- Design descriptions of candidate design solutions

- Criteria to measure performance of solutions

- Preference statements to indicate relative importance between criteria (weights, rank of criteria, etc.)

A wide range of methods are available to analysts aiming to support decision making in ship acquisition. The problem for the analyst is therefore to identify an adequate method for the decision context at hand. To the knowledge of the authors, there are currently no reviews of such methods for ship acquisition decision contexts. To critically evaluate the operational value of methods in ship acquisition, we will first explore previous applications and examine the type and nature of information available. We identify important method properties to take into account in method selection, before defining properties for 12 welltested and validated MCDM methods. Finally, we discuss the use of these methods in various decision contexts and offer a generic approach to method selection for ship design appraisals.

\section{Materials and methods}

\subsection{MCDM applications in ship acquisition}

The application of MCDM methods to appraise ship design has steadily grown during the last two decades. If we examine this body of the literature, as displayed in Table 1, we may make a few considerations with regard to characteristics of decision contexts in ship acquisition.

Firstly, our concern is with the type of data utilized in various decision contexts. If we consider measurement scales, we may differentiate between cardinal and ordinal scales. Ordinal scales only allow determining a rank order of elements in a set while cardinal scales (on interval or ratio level) additionally help determine the distance between elements. As an example, safety might be determined to be low, moderate or high on a verbal scale or cardinally determined by a continuous parameter such as accidental oil outflow as seen in (Papanikolaou et al. 2010). From previous literature, we see that criteria scales during conceptual and preliminary design more often are cardinal, while scales at the point of investment more often are on ordinal scales. This is coherent with the fact that maturity of the design description increases during the process, allowing for higher-level considerations in later stages of the acquisition process. Overall maintainability or reliability might for instance be better assessed in an ordinal fashion based on owner, designer and yard expertise, as seen in (Yang et al. 2009).

Secondly, and surprisingly, we see that the ranking of criteria is usually made in a cardinal manner during both design and investment appraisals. At the point of investment, this information should be readily available since owners may be able to express their preferences with this degree of precision if support from analysts is given. In the design process, preference statements on criteria without involvement of owners should intuitively be less precise or at least difficult to determine. When we further examine these case studies, we see that weights often are derived via the entropy method or eigenvector method. In the first approach, weights are not subjectively derived, but assigned to criteria based on the performance differences for alternatives across these criteria. More importance is allocated to criteria where alternatives have very different 
Table 1 Methods applied in ship acquisition decision contexts

\begin{tabular}{|c|c|c|c|c|}
\hline Decision context & Method & $\begin{array}{l}\text { Criteria } \\
\text { scales }\end{array}$ & $\begin{array}{l}\text { Preferences on } \\
\text { criteria }\end{array}$ & References \\
\hline \multirow{5}{*}{$\begin{array}{l}\text { Considerations during the design } \\
\text { process }\end{array}$} & Fuzzy TOPSIS & Mixed & Cardinal & Ölçer et al. (2004), Ölçer and Odabaşi (2005) \\
\hline & AHP, rigid least square & Cardinal & Cardinal & Song et al. (2006) \\
\hline & Evidential reasoning (ER) & Mixed & Cardinal & Xie et al. (2008) \\
\hline & TOPSIS, entropy weights & Cardinal & Cardinal & Xuebin (2009) \\
\hline & Ma, Fan, Huang method & Cardinal & Cardinal & Barone et al. (2005) \\
\hline \multirow{5}{*}{$\begin{array}{l}\text { Considerations at the point of } \\
\text { investment }\end{array}$} & AHP & Mixed & Cardinal & Leheta (2005), Rousos and Lee (2012) \\
\hline & Fuzzy AHP & Cardinal & Ordinal & Bulut et al. (2012, Duru et al. (2012) \\
\hline & Fuzzy AHP & Mixed & Cardinal & Bulut et al. (2010) \\
\hline & Fuzzy if-then rule & Mixed & Ordinal & Wibowo and Deng (2012) \\
\hline & ER (fuzzy) & Mixed & Cardinal & Yang et al. (2009) \\
\hline
\end{tabular}

outcomes and less importance to criteria where alternatives have similar outcomes. The eigenvector method derives weights based on statements of relative performance of pairs of criteria, often supported by a verbal (ordinal) scale that helps decision makers express their subjective opinion on the matter. These approaches reveal that quantitative weight assignment during the design process might be a difficult task, and the available data might be both ordinal and cardinal, depending on the involvement of owners and experience of the design team.

Table 1 also shows that with the exception of the fuzzy approach evidential reasoning (ER), TOPSIS and AHP are the main methods applied. These are highly compensatory as they permit trade-offs between advantages and disadvantages across criteria. If we further examine typical criteria used in these decision-making contexts, as summarized in Table 2, we see that these are rather heterogeneous. This raises concern of the compensatory nature of MCDM methods when applied to ship design appraisals. For instance, owners or designers might find it problematic that crew safety is sacrificed to improve maintainability of equipment. Another important point when appraising ship design is that sustainability performance is better safeguarded in methods that are not fully compensatory (Polatidis et al. 2006). If we revisit the design process and consider approaches for synthesizing solutions, we see that there is room for a nuanced perspective on whether or not compensation is allowed. Type of criteria and aspects covered are related to strategies for design development. One approach is to develop novel designs based on optimization models or other forms of creation (Cushing 2003; Erikstad 1996). These approaches often aim to maximize techno-economic performance subject to a set of constraints, as seen in (Papanikolaou et al. 2010; Žanić and Cudina 2009). In these instances, trade-offs are typically unproblematic. A second approach is to identify a reference vessel of known design to constitute a basis design, which is further developed into a solution meeting specific requirements of owners (Cushing 2003; Erikstad 1996). Selecting between existing solutions to identify the best reference vessel allows for diverse criteria modeling and utilization of validated empirical data from ship operations, as seen in (Xie et al. 2008). A general remark is that ship design appraisals should be used with less compensatory methods when the design description is rich and heterogeneity among criteria is high. This concern with regard to compensation also applies to appraisals at the point of investment, which, as previously mentioned, requires considering a diverse set of criteria.

\subsection{MCDM methods considered}

MCDM methods offer support for both design and selection problems. In design problems, multi-objective decision-making (MODM) methods implicitly define solutions. In selection, a discrete set of alternatives is given and further analyzed by multi-attrite decision-making (MADM) methods. Our assessment is applicable in situations where a decision problem has been structured such that the objectives and criteria of decision makers have been identified along with a set of admissible ship design alternatives. At this point, let us consider the problem $\operatorname{Max}\left\{k_{1}(a), \ldots, k_{m}(a) \mid a \in A\right\}$ where $A$ is a finite set of $n$ design alternatives and $F$ is a family of $m$ criteria to be maximized. For these situations, we will describe and evaluate 12 well-tested and validated MADM methods within three classes: elementary, outranking and value function. A brief description of the methods considered is provided in Table 3.

Elementary methods are simple approaches that do not require weights to be determined (Hwang and Yoon 1981). Although these methods consider problems from a multicriteria perspective, the ordering of alternatives is often built on the performance of one or a few criteria. From this 
Table 2 Criteria for ship design appraisals

\begin{tabular}{|c|c|c|c|}
\hline Criteria & References & Criteria & References \\
\hline Economic & & Technological & \\
\hline $\begin{array}{l}\text { Capital } \\
\text { expenditure }\end{array}$ & $\begin{array}{l}\text { Barone et al. (2005), Leheta (2005), Rousos and Lee (2012), } \\
\text { Song et al. (2006), Ölçer and Odabaşi (2005) }\end{array}$ & Maintainability & Wibowo and Deng (2012) \\
\hline $\begin{array}{l}\text { Operational } \\
\text { expenditures }\end{array}$ & Bulut et al. (2010), Ölçer and Odabaşi (2005) & Reliability & $\begin{array}{l}\text { Yang et al. (2009, Ölçer and Odabaşi } \\
\text { (2005) }\end{array}$ \\
\hline $\begin{array}{l}\text { Return on } \\
\text { investment } \\
\text { (ROI) }\end{array}$ & Bulut et al. (2012) & Producibility & Ölçer et al. (2004) \\
\hline $\begin{array}{l}\text { Required freight } \\
\text { rate (RFR) }\end{array}$ & Song et al. (2006), Xie et al. (2008) & Speed & $\begin{array}{l}\text { Bulut et al. (2010, 2012), Duru et al. } \\
\text { (2012), Leheta (2005), Wibowo and } \\
\text { Deng (2012) }\end{array}$ \\
\hline $\begin{array}{l}\text { Net present } \\
\text { value (NPV) }\end{array}$ & $\begin{array}{l}\text { Bulut et al. (2010), Rousos and Lee (2012), Song et al. (2006), } \\
\text { Xie et al. (2008) }\end{array}$ & $\begin{array}{l}\text { Payload } \\
\text { capacity }\end{array}$ & $\begin{array}{l}\text { Leheta (2005), Xuebin (2009), Ölçer } \\
\text { et al. (2004) }\end{array}$ \\
\hline $\begin{array}{l}\text { Return on } \\
\text { equity (ROE) }\end{array}$ & Bulut et al. (2010), Duru et al. (2012) & Maneuverability & $\begin{array}{l}\text { Xie et al. (2008, Ölçer and Odabaşi } \\
\text { (2005) }\end{array}$ \\
\hline $\begin{array}{l}\text { Internal rate of } \\
\text { return (IRR) }\end{array}$ & Leheta (2005), Rousos and Lee (2012), Song et al. (2006) & $\begin{array}{l}\text { Equipment } \\
\text { performance }\end{array}$ & Xie et al. (2008) \\
\hline Payback period & Song et al. (2006), Xie et al. (2008) & Noise & Ölçer and Odabaşi (2005) \\
\hline Hire base & Xie et al. (2008) & Vibration & Ölçer and Odabaşi (2005) \\
\hline Insurance cost & Wibowo and Deng (2012) & & Yang et al. (2009) \\
\hline Fuel cost & $\begin{array}{l}\text { Bulut et al. (2010, 2012), Duru et al. (2012), Leheta (2005), } \\
\text { Wibowo and Deng (2012), Yang et al. (2009)) }\end{array}$ & & \\
\hline Crew cost & Wibowo and Deng (2012), Yang et al. (2009) & & \\
\hline $\begin{array}{l}\text { Store } \\
\text { consumption }\end{array}$ & Yang et al. (2009) & & \\
\hline Safety & & Environmental & \\
\hline $\begin{array}{r}\text { Stability and } \\
\text { seakeeping }\end{array}$ & Leheta (2005), Xie et al. (2008), Ölçer et al. (2004) & Air emissions & Yang et al. (2009) \\
\hline Survivability & Ölçer et al. (2004) & $\begin{array}{l}\text { Life cycle } \\
\text { impacts }\end{array}$ & Ölçer et al. (2004) \\
\hline Fire protection & Xie et al. (2008) & $\begin{array}{l}\text { Pollution } \\
\text { prevention }\end{array}$ & Yang et al. (2009) \\
\hline Crew safety & Leheta (2005) & $\begin{array}{l}\text { Expected spill } \\
\text { size }\end{array}$ & Rousos and Lee (2012) \\
\hline
\end{tabular}

class, we examine the Lexicographic method and Maximax/Maximin.

Outranking methods attempt to evaluate the assertion that an alternative outranks another based on proof built from combining performance across criteria and importance of criteria. For any relation, criteria may be split into a concordant coalition supporting the assertion and a discordant coalition opposing it. The main difference between outranking methods is how concordance and discordance are measured and aggregated to produce a final ranking. ORESTE, Regime, ELECTRE II and III, MELCHIOR and PROMETHEE I and II are outranking methods considered in our review.
Value function methods combine utility/value functions and weights to compute an overall value of alternatives. In these approaches, weights represent scaling constants rendering criteria scales comparable. TOPSIS, MAVT, AHP and UTA are methods considered in our review belonging to this class.

\subsection{Evaluation properties}

MCDM method reviews usually involve mapping properties of methods onto characteristics of a decision context. Important concerns in identifying an appropriate method for decision contexts are the technical capabilities of 
Table 3 Methods considered in the review

\begin{tabular}{|c|c|c|c|}
\hline Class & Method & Description & References \\
\hline \multirow[t]{2}{*}{ Elementary } & $\begin{array}{l}\text { Maximax/ } \\
\text { Maximin }\end{array}$ & $\begin{array}{l}\text { Alternative with the best performance on its strongest criterion (Maximax) or its } \\
\text { weakest criterion (Maximin) is selected }\end{array}$ & See Hwang and Yoon (1981) \\
\hline & Lexicographic & $\begin{array}{l}\text { Alternatives are evaluated across an ordinal rank of criteria. Dominated } \\
\text { alternatives are eliminated, and tied alternatives are further examined across } \\
\text { the next criterion in the ordinal rank until a single alternative remains }\end{array}$ & \\
\hline \multirow[t]{6}{*}{ Outranking } & ORESTE & $\begin{array}{l}\text { Ordinal ranking of alternatives and criteria is used to construct a complete } \\
\text { ranking on the set of alternatives before indifference and conflict analysis is } \\
\text { conducted to produce a final rank of alternatives }\end{array}$ & See Roubens (1982) \\
\hline & Regime & $\begin{array}{l}\text { Pairwise comparisons of alternatives are used to construct a Regime matrix with } \\
\text { indicators for dominance, equivalence and non-dominance across criteria. A } \\
\text { total preorder is obtained by aggregating these weighted scores }\end{array}$ & See Hinloopen et al. (1983) \\
\hline & ELECTRE II & $\begin{array}{l}\text { Concordance and discordance indices are computed for all pairs of actions and } \\
\text { used along with thresholds to build strong and weak outranking relations. } \\
\text { These are further exploited to provide a partial preorder (semi-order) }\end{array}$ & See Roy and Bertier (1971) \\
\hline & ELECTRE III & $\begin{array}{l}\text { Concordance and discordance for an outranking relation are determined with } \\
\text { pseudo-criteria and used to build a credibility index that offers a fuzzy } \\
\text { interpretation of outranking relations. The index is further exploited to provide } \\
\text { a partial preorder (semi-order) of alternatives }\end{array}$ & See Roy (1978) \\
\hline & MELCHIOR & $\begin{array}{l}\text { Criteria importance is determined by a binary relation before concordance and } \\
\text { discordance indices are built and exploited to provide a partial preorder (semi- } \\
\text { order) }\end{array}$ & See Leclercq (1984) \\
\hline & $\begin{array}{l}\text { PROMETHEE } \\
\text { (I and II) }\end{array}$ & $\begin{array}{l}\text { A preference function is defined on each criterion reflecting the preference } \\
\text { intensity over deviations of criteria values. The outranking algorithm } \\
\text { comparatively scores alternatives on each decision criterion and establishes } \\
\text { their overall rank order through their weighted relative dominance over other } \\
\text { alternatives across all criteria }\end{array}$ & See Brans and Vincke (1985) \\
\hline \multirow[t]{4}{*}{$\begin{array}{l}\text { Value } \\
\text { function }\end{array}$} & TOPSIS & $\begin{array}{l}\text { Positive and negative ideal points are defined for all criteria, and alternatives are } \\
\text { ranked based on their aggregated distance to these points }\end{array}$ & See Hwang and Yoon (1981) \\
\hline & MAVT & $\begin{array}{l}\text { A partial value function for each criterion is built, and trade-offs between all } \\
\text { pairs of criteria are examined to obtain weights. The aggregated value of } \\
\text { alternatives is used to build a total preorder }\end{array}$ & $\begin{array}{l}\text { See Fishburn (1970) and } \\
\text { Keeney and Raiffa (1993) }\end{array}$ \\
\hline & AHP & $\begin{array}{l}\text { Pairwise comparisons of criteria and alternatives are used to derive weights and } \\
\text { score alternatives. The aggregated value of alternatives is used to build a total } \\
\text { preorder }\end{array}$ & See Saaty (1987) \\
\hline & UTA & $\begin{array}{l}\text { An ordinal rank of a subset of alternatives is disaggregated via a linear program } \\
\text { to deduce marginal utility functions. These are further used to rank the full set } \\
\text { of alternatives, giving a total preorder }\end{array}$ & $\begin{array}{l}\text { See Jacquet-Lagreze and } \\
\text { Siskos (1982) }\end{array}$ \\
\hline
\end{tabular}

methods in dealing with the available data, and their practical value, as shown in Table 4.

Technical properties cover permissible scales for input data and the degree of compensation allowed in the preference structure. As shown in Sect. 2.1, this could significantly differ between decision contexts. Data requirements relate to how alternatives in the set $A$ are ranked based on criteria in $F$ and furthermore how criteria in $F$ are ranked according to importance, inspired by a method assessment framework applied by Moffett and Sarkar (2006). We will distinguish between methods that utilize ordinal or cardinal scales to measure this information. Ordinal scales are generally considered "weaker" than cardinal scales as they contain much less information (Roberts 1979), but are on the other hand more flexible as they may be applied in situations where information is ordinal, cardinal or mixed (Moffett and Sarkar 2006). Furthermore, the extent to which the preference structure allows compensation between good and poor performance along criteria is an important technical property as it potentially affects how well a preferred solution balances sustainability aspects (Guitouni and Martel 1998; Polatidis et al. 2006; Roy and Słowiński 2013).

Practical properties relate to the cognitive burden put on decision makers during method application. Modeling requirements with regard to preference information is an important property, with extensive requirements reducing the applicability of methods in decision situations (De 
Table 4 Selected properties for method evaluation

\begin{tabular}{lll}
\hline Aspect & Property & Description \\
\hline Technical & $\begin{array}{c}\text { Ranking of } \\
\text { alternatives } \\
\text { Ranking of criteria } \\
\text { Compensation }\end{array}$ & $\begin{array}{c}\text { Describes whether the method can handle ordinal and/or cardinal criteria } \\
\text { Describes whether the method requires no, ordinal or cardinal preference information } \\
\text { Describes to what extent the method is compensatory. For a strong sustainability interpretation, none or } \\
\text { partial compensation is preferred }\end{array}$ \\
$\begin{array}{ccc}\text { Computational } \\
\text { complexity } \\
\text { Modeling } \\
\text { requirements }\end{array}$ & $\begin{array}{c}\text { Evaluation of the computational complexity in the model. Relates to transparency and intuition in } \\
\text { aggregation/exploitation }\end{array}$ \\
& Requirements for preference modeling. Based on preference information necessary to induce an order on the \\
& set of alternatives
\end{tabular}

Montis et al. 2005). The further processing of this information along with additional information may create a distance between the decision maker and data. An important practical goal is therefore to ensure that decision makers are able to understand and accept data processing (De Montis et al. 2005; Sen and Yang 1998; Stewart 2005), which motivates the consideration of computational complexity of methods as another practical property in our method evaluation.

\section{Results and discussion}

In this section, method properties defined in Table 4 are evaluated based on examination of method algorithms and supporting literature. These results are summarized in Table 5 and further used for discussing and recommending methods for ship acquisition.

\subsection{Evaluation of technical properties}

When evaluating the property ranking of alternatives, we focus on the restrictions methods put on criteria with regard to measurement scales. This is related to how the information is utilized, often together with preference statements, to induce an order on the set of alternatives.

Both elementary methods included in this review permit ordinal ranking of alternatives as this is the only performance information necessary to produce an order. The outranking methods ORESTE and Regime also share this property. Ordinal criteria may also be used in ELECTRE II, provided that decision makers are able to define veto thresholds to be utilized in determining the discordance index. This requires that ordinal criteria have a sufficient amount of evaluation grades to support a meaningful modeling of these thresholds. The same applies to MELCHIOR, which requires both performance and indifference thresholds for criteria. ELECTRE III is better suited for problems with cardinal criteria scales (Belton and Stewart 2002; De Montis et al. 2005; Moffett and Sarkar 2006) as concordance and discordance indices are cardinal. In PROMETHEE I and II, six preference functions are provided to model preference intensity on deviations along criteria scales, several of which are compatible with criteria on ordinal scales. Value function methods may be considered entirely cardinal with regard to ranking of alternatives. The basic approach of aggregating preference and performance information into an overall value is impossible with an ordinal scale where distances between points are undetermined.

If we consider scales for preference information in the form of ranking of criteria, a main distinction can be made between those methods that require determination of weights and those which do not. Maximax/Maximin does not require any such information as it implicitly allocates all importance to the criterion along which an alternative has its best or worst performance. Next, we have methods that only require an ordinal ranking of criteria such as the Lexicographic method, ORESTE, Regime and MELCHIOR. All other methods belonging to either the outranking or the value function class utilize cardinal ranking of criteria in the form of weights.

Degree of compensation is a property of the preference structure, and we may distinguish between no, partial or complete compensation in methods. In general, value function methods that aggregate overall value of alternatives utilizing weights that are interpreted as scaling constants are highly compensatory (Roy and Słowiński 2013). TOPSIS and UTA may be considered fully compensatory as they assume linear preferences (Guitouni and Martel 1998; Sen and Yang 1998). In our review, MAVT and AHP will also be considered fully compensatory since there is a complete trade-off between alternatives with regard to the weighted value of alternatives across criteria. Elementary methods are non-compensatory as there are no trade-offs between good and poor performance. Outranking methods 
Table 5 Method properties

\begin{tabular}{|c|c|c|c|c|c|c|}
\hline \multirow[t]{2}{*}{ Class } & \multirow[t]{2}{*}{ Method } & \multicolumn{3}{|c|}{ Technical aspects } & \multicolumn{2}{|c|}{ Practical aspects } \\
\hline & & $\begin{array}{l}\text { Ranking of } \\
\text { alternatives }\end{array}$ & $\begin{array}{l}\text { Ranking of } \\
\text { criteria }\end{array}$ & $\begin{array}{l}\text { Degree of } \\
\text { compensation }\end{array}$ & Complexity & $\begin{array}{l}\text { Modeling } \\
\text { requirements }\end{array}$ \\
\hline \multirow[t]{2}{*}{ Elementary } & Maximax/Maximin & Ordinal & None & None & Low & Low \\
\hline & Lexicographic & Ordinal & Ordinal & None & Low & Low \\
\hline \multirow[t]{6}{*}{ Outranking } & ORESTE & Ordinal & Ordinal & Partial & Medium & Medium \\
\hline & Regime & Ordinal & Ordinal & Partial & High & Low \\
\hline & ELECTRE II & Ordinal & Cardinal & Partial & High & Medium \\
\hline & ELECTRE III & Cardinal & Cardinal & Partial & High & High \\
\hline & MELCHIOR & Ordinal & Ordinal & Partial & High & High \\
\hline & $\begin{array}{l}\text { PROMETHEE (I and } \\
\text { II) }\end{array}$ & Ordinal & Cardinal & Partial & Medium & Medium \\
\hline \multirow{4}{*}{$\begin{array}{l}\text { Value } \\
\text { function }\end{array}$} & TOPSIS & Cardinal & Cardinal & Full & Low & Low \\
\hline & MAVT & Cardinal & Cardinal & Full & Low & High \\
\hline & AHP & Cardinal & Cardinal & Full & Low & High \\
\hline & UTA & Cardinal & Cardinal & Full & Medium & Low \\
\hline
\end{tabular}

building on concepts of concordance and discordance may be regarded only partially compensatory (Roy and Słowiński 2013).

\subsection{Evaluation of practical properties}

Computational complexity of methods concerns how input data in the form of preferences and scoring of alternatives are transformed to a final rank order. Some algorithms are seemingly intuitive in the sense that non-analysts may understand their underlying principles. Elementary methods are generally straightforward and easy to understand for non-analysts. The same can be said for value function methods, where aggregation of preferences and performance into a single overall value or utility is a rather transparent procedure (De Montis et al. 2005). MAVT, AHP and TOPSIS may all be categorized as having low computational complexity. UTA follows the opposite strategy by disaggregating values. The ordinal regression procedure by which partial value functions are obtained may be considered mathematically complex, but the concept of preference regression should be possible to communicate to decision makers lacking experience or knowledge of such methods. Outranking methods are generally considered more complex than value function methods. The exploitation procedure in ELECTRE methods is rather opaque and may be difficult to understand for decision makers without experience or knowledge of the method (Belton and Stewart 2002; De Montis et al. 2005; Moghaddam et al. 2011). The same applies to MELCHIOR which exploits outranking relations in a similar manner to
ELECTRE III. The concept of concordance utilized to build a rank order in Regime is straightforward if weights are known cardinally. If not, a cumbersome regime analysis must be undertaken to identify weights, which reduces the transparency of the decision-making procedure (De Montis et al. 2005). The first phase of ORESTE, where a complete preorder (global ranks) is built, rankings of criteria and alternatives are aggregated in a transparent manner. However, the meaning of threshold levels is more abstract in ORESTE than in ELECTRE and MELCHIOR methods, as they are defined on preference intensities as opposed to criteria. The following procedure whereby preference intensities and threshold levels are used to arrive at a final order may also be considered unintuitive. However, the representation of the procedure by if-then rules at least illustrates the traceability between the global ranks and the final order. PROMETHEE may be an exception from other outranking methods as it is usually considered a rather intuitive approach. In PROMETHEE II where a complete ranking is provided, the net flow is comparable with a utility function (Brans and Mareschal 2005).

Elementary methods are considered among the simplest along the properties of modeling requirements. Maximax/ Maximin requires no information at all, and the Lexicographic method only requires an ordinal rank of criteria. The same applies to Regime, which only requires ordinal ranks of criteria. Next, we find methods that only require cardinal weights, such as TOPSIS, and an ordinal rank of alternatives, such as UTA. These may also be considered low on modeling requirements when compared to other 
MCDM methods. More cumbersome are those that require ordinal/cardinal ranking of criteria in addition to determination of thresholds. In this group, we find ELECTRE II and III, PROMETHEE, MELCHIOR and ORESTE. The use of quasi-criteria in ELECTRE III is on the one hand a very useful approach to dealing with uncertainty and ambiguity (Figueira et al. 2005), but may on the other hand also induce a heavy cognitive burden on decision makers as they must be defined for all criteria. The meaning of these thresholds is unclear, and guidance on how to define them is missing (Belton and Stewart 2002). MELCHIOR suffers from the same as both indifference and preference thresholds must be defined on each criterion. ELECTRE II may be considered less time-consuming as it does not require defining preference and indifference thresholds for criteria. ORESTE also requires determining thresholds for preference, indifference and incomparability, but unlike ELECTRE III and MELCHIOR, these thresholds are defined on preference intensities and not for each criterion. In PROMETHEE, the modeling time is dependent on the preference function defined on each criterion. Modeling requirements are also considered high in MAVT/MAUT and AHP. In MAVT/MAUT, the determination of partial value/utility functions and trade-off constants makes preference elicitation an extensive procedure (De Montis et al. 2005; Moffett and Sarkar 2006). The same applies to AHP, which requires pairwise comparisons of criteria and alternatives (Polatidis et al. 2006).

\subsection{Recommendation for use}

As shown in Table 5, there is a great diversity among methods with respect to the selected properties. In the following paragraphs, we will critically discuss the operational value of methods for some decision contexts where ship design is being appraised, by examining problem characteristics with these method properties.

If we consider concept design, where primarily technoeconomic criteria measured on a cardinal scale are available and owners are not involved, UTA exhibits technical and practical properties useful in assessing a set of candidate design solutions. It is especially useful in a situation where an optimization routine has been applied, generating an extensive set of Pareto optimal design solutions, as seen, for example, in Xuebin (2009). Although UTA implies a cardinal interpretation of ranking of criteria, designers are not required to make explicit quantitative judgements about the relative importance of criteria. The ordinal ranking of a subset of alternatives should be given to experienced designers that are able to make an aggregated judgement considering all aspects of design simultaneously. We emphasize that this method generally should only be applied when trade-offs between good and poor performance along criteria are permitted. This is usually the case when only technical and economic considerations are made of acceptable candidate solutions. As it is an additive value method, it also follows that criteria must be preferentially independent in the mind of decision makers, i.e., they are able to consider the relative importance between any two criteria without concern of the state of any other criteria, provided that their levels are fixed (Keeney and Raiffa 1993).

If we further imagine a situation where owners participate in the design decision-making process at early phases, TOPSIS is a promising method as it utilizes cardinal criteria and cardinal ranking of criteria. In addition, it is considered very practical with minimum requirements to preference information in addition to offering an intuitive data processing procedure. In addition to weights, owners and designers must determine positive and negative ideal points to produce the rank. A simple approach to this could be to define ideal points based on extreme criteria values of alternatives in the setup for consideration, but care must then be given to potential problems with rank reversals if the initial set of alternatives considered is altered (GarcíaCascales and Lamata 2012). This rearrangement of an order based on the introduction or elimination of a nonoptimal alternative is a rather counterintuitive phenomenon from a decision maker perspective. Determining thresholds not dependent on the set of alternatives considered could reduce the likelihood of this problem occurring, as well as adopting more robust variants of the methods (GarcíaCascales and Lamata 2012). Since the method is rather sensitive to weights (Sen and Yang 1998), the determination of these should also follow a rather rigorous process with regard to elicitation and validation. We also mention ELECTRE III as a potential method in these situations if compensation is not allowed. It may be considered rather unpractical, but is the only approach considered in this review that utilizes cardinal ranking of criteria and alternatives without allowing full compensation.

Moving on to situations where design descriptions are more mature and rich, allowing problem definitions with criteria on both ordinal and cardinal scales, a new set of methods comes to attention. Particularly outranking methods offers interesting properties in situations where criteria scales are mixed and only limited compensation is permitted. If we again are faced with the lack of precise preference information from owners or other parties considered problem holders, ORESTE may be a useful method. Designers with expert knowledge and experience could provide an ordinal rank of criteria reflecting a perceived importance rank owners might have. The main drawback of this method is that it requires determining thresholds of indifference and preference, which is particularly difficult as they are defined on preference intensities 


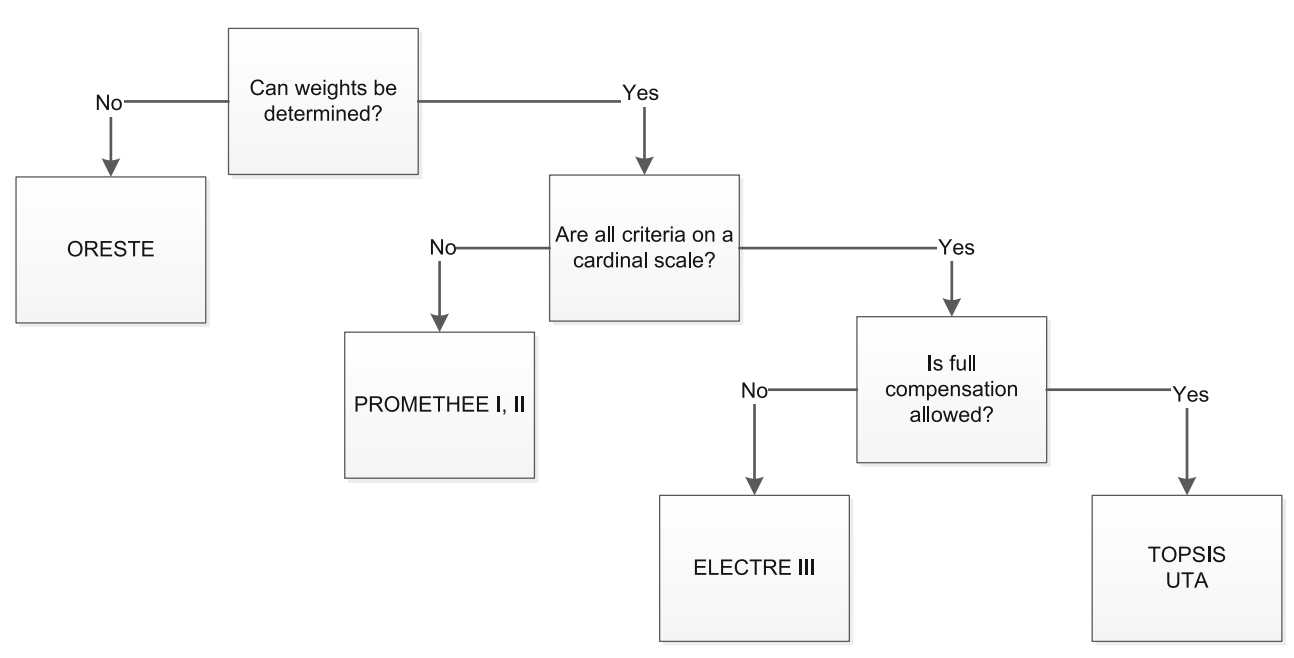

Fig. 1 Recommendation of methods for ship design appraisals

and not criteria themselves (as in, for example, ELECTRE III or MELCHIOR). If a decision support software or analysts with MCDM-capacities are available, this elicitation could be well facilitated. Since ORESTE ranks all alternatives on an ordinal scale across criteria, some information may be considered "lost" as the information utilized is weaker than the original cardinal nature of some criteria provided allow for. MELCHIOR also offers many of the same properties. Interpretation of threshold levels is more intuitive as they are defined on criteria, but this process can be rather time-consuming if the set of criteria is large. Data processing is also more complex than in ORESTE.

Finally, we consider a decision context, either in design or at the point of investment, where owners are involved and design descriptions are complete. This turns our attention to PROMETHEE I and II, which combine ordinal ranking of alternatives with cardinal ranking of criteria. In addition to being intuitive and moderately time-consuming, decision support software offering graphical illustrations of alternatives and criteria in the GAIA plane helps explore the decision structure further. Projection by means of principal component analysis helps preserve as much information as possible in this illustration where the similarity of criteria, their discriminant power and differences between alternatives relative to criteria may be interpreted visually (Brans and Mareschal 2005). This feature is useful in exploring the problem and possible alternatives prior to making long-term economic and organizational commitments of the magnitude that ship acquisition entails. As PROMETHEE I and PROMETHEE II primarily differ with regard to what preference structure is obtained, we recommend evaluating whether the incomparability relation is of interest in the decision process. This concept may be somewhat difficult to grasp at first hand for decision makers, and if so, PROMETHEE II may be used.

\section{Summary and conclusion}

Our review has compared $12 \mathrm{MCDM}$ methods with regard to their technical and practical properties and further evaluated their applicability in multi-criteria appraisals in ship acquisition. Results show that several methods not applied before offer promising properties to common decision contexts occurring throughout the ship acquisition process. Our discussion has illuminated some typical decision contexts and suggested appropriate methods based on the characteristics of the problem environment and properties of methods.

We further summarize our reasoning in Fig. 1 to provide a more generic method selection procedure applicable to all decision contexts for sustainability appraisal in ship acquisition. This procedure may not be considered exhaustive, as decision contexts might be highly diverse.

If we compare our results to previous applications of MCDM methods for ship design appraisals, we see that TOPSIS is the only method both previously applied and currently recommended. The widely recognized and applied method AHP is for instance not recommended. This deviance stems from the fact that it is penalized for its cumbersome preference modeling requirements. Since TOPSIS is equally transparent and less time-consuming, it should be considered a good replacement in any situation AHP has previously been applied. This review has furthermore not rewarded AHP for its preference elicitation technique, which allows deriving weights and scoring alternatives by the assistance of verbal scales. In these 
situations, we refer to methods that keep intact this ordinal nature of information, such as ORESTE or even MELCHIOR. We also acknowledge that MAVT may map ordinal information onto a cardinal scale in a rather elegant, though time-consuming manner. This actually makes MAVT suitable in both situations where alternatives are ranked on mixed scales or entirely on cardinal scales. Our review shows that for the first situation, PROMETHEE is considered a better and less time-consuming method (unless full compensation is explicitly desired). In the second situation, the simple methods TOPSIS and UTA have the same technical properties as MAVT. In this data situation, we also recommend ELECTRE III if full compensation is not allowed.

Our assessment does not find any of the elementary methods to be suitable for appraisals in ship acquisition. This is mainly due to their tendency to produce a final order based on only one or a very limited amount of criteria. Considering the complexity and diversity of criteria and the magnitude of commitments made in an acquisition, these approaches are considered too simplistic.

Acknowledgments This article was developed within the project Innovation in Global Maritime Production-2020 (IGLO-MP-2020), and the authors acknowledge funding by the Norwegian Research Council, Ulstein International AS, Siemens AS and Pon Power AS. The authors also greatly appreciate constructive feedback from two anonymous reviewers.

Open Access This article is distributed under the terms of the Creative Commons Attribution 4.0 International License (http://crea tivecommons.org/licenses/by/4.0/), which permits unrestricted use, distribution, and reproduction in any medium, provided you give appropriate credit to the original author(s) and the source, provide a link to the Creative Commons license, and indicate if changes were made.

\section{References}

Andrews D, Papanikolaou A, Erichsen S, Vasudevan S (2009) State of the art report on design methodology. Paper presented at the 10th International Marine Design Conference, Trondheim, Norway

Barone M, Begovic E, Bertorello C, Stella M (2005) Preference communication in multiattribute procedures for optimised ship design. Paper presented at the 12th International Congress of the International Maritime Association of the Mediterranean, IMAM 2005 - Maritime Transportation and Exploitation of Ocean and Coastal Resources, Lisboa

Belton V, Stewart TJ (2002) Multiple criteria decision analysis: an integrated approach. Kluwer Academic, Boston

Brans J-P, Mareschal B (2005) Promethee methods. In: Multiple criteria decision analysis: state of the art surveys, vol 78 . International Series in Operations Research \& Management Science. Springer New York, pp 163-186. doi:10.1007/0-38723081-5_5

Brans JP, Vincke P (1985) A preference ranking organisation method (The PROMETHEE method for multiple criteria decisionmaking). Manage Sci 31:647-656. doi:10.2307/2631441
Bulut E, Yoshida S, Duru O (2010) Cognitive model of dry bulk carrier investment decision by utilizing analytic hierarchy process. Paper presented at the 8th IEEE International Conference on Industrial Informatics, INDIN 2010, Osaka

Bulut E, Duru O, Keçeci T, Yoshida S (2012) Use of consistency index, expert prioritization and direct numerical inputs for generic fuzzy-AHP modeling: a process model for shipping asset management. Expert Syst Appl 39:1911-1923. doi:10.1016/j. eswa.2011.08.056

Coyne RD (1990) Knowledge-based design systems. Addison-Wesley, Reading

Cushing CR (2003) The ship acquisition process. In: Lamb T (ed) Ship design and construction, vol 1. Society of Naval Architects and Marine Engineers (SNAME), Jersey City

De Montis A, De Toro P, Droste-Franke B, Omann I, Stagl S (2005) Assessing the quality of different MCDA methods. In: Getzner M, Spash CL, Stagl S (eds) Alternatives for environmental valuation. Routledge, London, pp 99-133

Dokkum Kv (2011) Ship knowledge: ship design, construction and operation. DOKMAR, Enkhuizen

Duru O, Bulut E, Yoshida S (2012) Regime switching fuzzy AHP model for choice-varying priorities problem and expert consistency prioritization: a cubic fuzzy-priority matrix design. Expert Syst Appl 39:4954-4964. doi:10.1016/j.eswa.2011.10.020

Erikstad SO (1996) A decision support model for preliminary ship design vol 1996:111. Doktor ingeniøravhandling. NTH, Trondheim

Erikstad SO, Andrews D (2015) State of the art report on design methodology. Paper presented at the 12th International Marine Design Conference, Tokyo, Japan

Eyres DJ, Bruce GJ (2012) Ship construction. Elsevier/ButterworthHeinemann, Amsterdam

Figueira J, Mousseau V, Roy B (2005) Electre methods. In: Multiple criteria decision analysis: state of the art surveys, vol 78 . International Series in Operations Research \& Management Science. Springer, New York, pp 133-153. doi:10.1007/0-38723081-5_4

Fishburn PC (1970) Utility theory for decision making. Wiley, New York

García-Cascales MS, Lamata MT (2012) On rank reversal and TOPSIS method. Math Comput Model 56:123-132. doi:10.1016/ j.mcm.2011.12.022

Guitouni A, Martel JM (1998) Tentative guidelines to help choosing an appropriate MCDA method. Eur J Oper Res 109:501-521

Hinloopen E, Nijkamp P, Rietveld P (1983) Qualitative discrete multiple criteria choice models in regional planning. Reg Sci Urban Econ 13:77-102. doi:10.1016/0166-0462(83)90006-6

Hwang C-L, Yoon K (1981) Multiple attribute decision making: methods and applications : a state-of-the-art survey. Springer, Berlin

Jacquet-Lagreze E, Siskos J (1982) Assessing a set of additive utility functions for multicriteria decision-making, the UTA method. Eur J Oper Res 10:151-164. doi:10.1016/0377-2217(82)90155-2

Keeney RL, Raiffa H (1993) Decisions with multiple objectives: preferences and value tradeoffs. Cambridge University Press, Cambridge

Leclercq JP (1984) Propositions d'extension de la notion de dominance en présence de relations d'ordre sur les pseudocritères: MELCHIOR Revue Belge de Recherche Opérationnelle, de Statistique et d'Informatique 24:32-46

Leheta HW (2005) A multi-criteria stern trawler selection model using the analytic hierarchy process. In: 12th International Congress of the International Maritime Association of the Mediterranean, IMAM 2005-Maritime Transportation and Exploitation of Ocean and Coastal Resources, Lisboa, pp 1251-1257 
Mistree F, Smith WF, Bras BA, Allen JK, Muster D (1990) Decisionbased design. A contemporary paradigm for ship design. In: 1990 SNAME Annual Meeting, Jersey City, NJ, United States. Publ by Soc of Naval Architects \& Marine Engineers, pp 565-597

Mistree F, Smith WF, Kamal SZ, Bras BA (1991) Designing decisions: axioms, models and marine applications. Paper presented at the Fourth International Marine Systems Design Conference, Kobe, Japan

Moffett A, Sarkar S (2006) Incorporating multiple criteria into the design of conservation area networks: a minireview with recommendations. Divers Distrib 12:125-137. doi:10.1111/j. 1366-9516.2005.00202.x

Moghaddam NB, Nasiri M, Mousavi SM (2011) An appropriate multiple criteria decision making method for solving electricity planning problems, addressing sustainability issue. Int $\mathrm{J}$ Environ Sci Technol 8:605-620. doi:10.1007/BF03326246

Nowacki H (2010) Five decades of computer-aided ship design CAD. Comput Aided Des 42:956-969. doi:10.1016/j.cad.2009.07.006

Ölçer Aİ, Odabaşi AY (2005) A new fuzzy multiple attributive group decision making methodology and its application to propulsion/manoeuvring system selection problem European. J Oper Res 166:93-114. doi:10.1016/j.ejor.2004.02.010

Ölçer AI, Alkaner S, Turan O (2004) Integrated multiple attributive decision support system for producibility evaluation in ship design. J Ship Prod 20:147-163

Pahl G, Beitz W, Feldhusen J, Grote K-H, Wallace K, Blessing L (2007) Engineering design: a systematic approach. Springer, London

Papalambros PY, Wilde DJ (2000) Principles of optimal design: modeling and computation. Cambridge University Press, Cambridge

Papanikolaou A, Zaraphonitis G, Boulougouris E, Langbecker U, Matho S, Sames P (2010) Multi-objective optimization of oil tanker design. J Mar Sci Technol 15:359-373

Polatidis H, Haralambopoulos DA, Munda G, Vreeker R (2006) Selecting an appropriate multi-criteria decision analysis technique for renewable energy planning. Energy Sour 1:181-193. doi: $10.1080 / 009083190881607$

Roberts FS (1979) Measurement theory with applications to decision making, utility and the social sciences. Addison-Wesley, Reading

Roubens M (1982) Preference relations on actions and criteria in multicriteria decision making. Eur J Oper Res 10:51-55. doi:10. 1016/0377-2217(82)90131-X
Rousos EP, Lee BS (2012) Multicriteria analysis in shipping investment evaluation. Maritime Policy Manag 39:423-442

Roy B (1978) ELECTRE III: Un algorithme de classement fondé sur une représentation floue des préférences en présence de critères multiples Cahiers du CERO 20:3-24

Roy B, Bertier P (1971) La Méthode ELECTRE II, Note de Travail 142, SEMA-METRA Metra International

Roy B, Słowiński R (2013) Questions guiding the choice of a multicriteria decision aiding method EURO. J Decis Process 1:69-97. doi:10.1007/s40070-013-0004-7

Saaty RW (1987) The analytic hierarchy process-what it is and how it is used. Math Model 9:161-176. doi:10.1016/02700255(87)90473-8

Sen P, Yang J-B (1998) Multiple criteria decision support in engineering design. Springer, London

Song S, Hua-Jun L, Asme (2006) Study on ship form technical and economic evaluation ds based on interactive MCDM. In: Proceedings of the 25th international conference on offshore mechanics and arctic engineering, vol 2. Amer Soc Mechanical Engineers, New York

Stewart T (2005) Dealing with Uncertainties in MCDA. In: Multiple criteria decision analysis: state of the art surveys, vol 78 . International Series in Operations Research \& Management Science. Springer, New York, pp 445-466. doi:10.1007/0-38723081-5_11

Wibowo S, Deng H (2012) Intelligent decision support for effectively evaluating and selecting ships under uncertainty in marine transportation. Expert Syst Appl 39:6911-6920

Wijnolst N, Wergeland T (2009) Shipping innovation. IOS Press, Amsterdam

Xie X, Xu DL, Yang JB, Wang J, Ren J, Yu S (2008) Ship selection using a multiple-criteria synthesis approach. J Mar Sci Technol 13:50-62

Xuebin L (2009) Multiobjective optimization and multiattribute decision making study of ship's principal parameters in conceptual design. J Ship Res 53:83-92

Yang ZL, Mastralis L, Bonsall S, Wang J (2009) Incorporating uncertainty and multiple criteria in vessel selection proceedings of the institution of mechanical engineers part M. J Eng Marit Environ 223:177-188

Žanić V, Čudina P (2009) Multiattribute decision making methodology in the concept design of tankers and bulk carriers. Brodogradnja 60:19-43 